PACS 75.47.Np, 75.50.Ww

\title{
Magnetic hysteresis properties of the hard magnetic Fe-25\%Cr-10\%Co-2\%Mo-0,5\%Si powder alloy
}

\author{
T.A. Vompe ${ }^{\dagger}$ I.M. Milyaev, V.S. Yusupov \\ †tvompe@gmail.com
}

Baikov Institute of Metallurgy and Materials Science, Russian Academy of Sciences, 49 Leninskii prospect, Moscow, 119991 Russia

Hard magnetic materials of Fe-Cr-Co system are widely used in production of compact permanent magnets due to their magnetic and mechanic properties. Currently, there is an intensive search for economically alloyed and/or hard magnetic materials without rare-earth metals. The investigation of alloys with low content of expensive cobalt is an actual task. In this work the experimental investigation of the magnetic hysteresis properties $\left(\mathrm{B}_{r}, \mathrm{H}_{\mathrm{c}}(\mathrm{BH})_{\max }\right)$ of the magnetically hard powder alloy Fe-25\%Cr-10\%Co-2\%Mo-0,5\%Si was performed by the method of design of experiments (DOE). Starting temperature of the treatment and cooling rate in the magnetic field were variable. The samples were made by the methods of powder metallurgy. Regression equation for magnetic properties $\left(\mathrm{B}_{\mathrm{r}}, \mathrm{H}_{\mathrm{c}},(\mathrm{BH})_{\max }\right)$, standardized Pareto charts and sections of the response surface plots were made on the base of results of heat treatment according to selected parameters of heat treatment. It was shown that the value of coercive force $\mathrm{H}_{\mathrm{c}}$ and maximum energy product $(\mathrm{BH})_{\text {max }}$ are sensitive to starting temperature and cooling rate of the alloy, and residual induction $\mathrm{B}_{\mathrm{r}}$ are not sensitive to selected parameters. Proposed heat treatment modes made it possible to receive the following magnetic hysteresis properties on this alloy: coercive force $\mathrm{H}_{\mathrm{c}} 14,8-30,8 \mathrm{kA} / \mathrm{m}$, maximum energy product $(\mathrm{BH})_{\max }$ $6,0-20,1 \mathrm{~kJ} / \mathrm{m}^{3}$ and residual induction $\mathrm{B}_{\mathrm{r}} 1,20-1,35 \mathrm{~T}$. The investigated alloy can be used as the material for rotor production for synchronous hysteresis motors.

Keywords: magnetic properties, hard magnetic alloys, coercive force, residual induction, heat treatment.

\section{Introduction}

Hard magnetic materials are used for production of permanent magnets. The alloys based on the Fe-Cr-Co system are widely used due to attractive combination of their magnetic and mechanical properties, temperature and corrosion stability. As compared with other hard magnetic alloys based on systems Fe-Co-V, Fe-Al-Ni-Co-Cu-Ti, and compounds $\mathrm{SmCo}_{5}$ and $\mathrm{Sm}_{2} \mathrm{Co}_{17}, \mathrm{Fe}-\mathrm{Cr}$-Co alloys contains less amount of expensive and scarce cobalt, and they don't contain nickel and rare-earth materials. Nevertheless the investigations aimed at reducing cobalt content in hard magnetic alloy $\mathrm{Fe}-\mathrm{Cr}-\mathrm{Co}$ [1-2] are still of interest.

Some advantages of Fe-Cr-Co alloys with cobalt content up to 12 wt. \% were pointed out in the works [3-5]: material cheapening due to lower cobalt content, better ductility, slow kinetics of phase transformations which allow improving repeatability of results, because structure and magnetic properties of the alloys are sensitive to decomposition temperature.

Previously it was shown that Fe-Cr-Co alloys with 15 wt. \% of cobalt can be used for production of rotors for synchronous hysteresis motors (SHM) [6]. It is important for such alloys with one and the same chemical compounds to have the possibility to get different levels of magnetic hysteresis properties.

The purpose of this work is to study the level of magnetic hysteresis properties $\left(\mathrm{B}_{\mathrm{r}} \mathrm{H}_{\mathrm{c}},(\mathrm{BH})_{\max }\right)$ in the hard magnetic powder alloy $\mathrm{Fe}-25 \% \mathrm{Cr}-10 \% \mathrm{Co}-2 \% \mathrm{Mo}-0,5 \% \mathrm{Si}$ depending on different heat treatment.

\section{Materials and experimental techniques}

The hard magnetic alloy Fe-25\%Cr-10\%Co- $2 \% \mathrm{Mo}-0,5 \% \mathrm{Si}$ (wt. \%) was selected as a material for the study. The samples were produced by powder metallurgy. Industrial high purity powders of iron VS, chrome, PHS-1, cobalt PK-1N (GOST 9721-79) and small additions of molybdenum and silicon powders with particles size less than $40 \mu \mathrm{m}$ were used.

Powders with certain granulometric composition were mixed in turbulence mixer S 2.0 "Turbula" for 81 minutes. Compacting was performed by a single-ended pressing on a manual press KNUTH-130042 using zinc stearate in a detachable matrix with inner diameter $13,6 \mathrm{~mm}$ under the pressure of $600 \mathrm{MPa}$. Relative density of wet compacts was $76,7-77,9 \%$. Wet-pressed samples were sintered for 2,5 hours at the temperature of $1420^{\circ} \mathrm{C}$ in a shaft furnace SShV-1,25/ $24-\mathrm{I} 1$ in $10^{-2} \mathrm{~Pa}$ vacuum. Difference between the top and the bottom diameters after sintering was no more than 0,2 $\mathrm{mm}$. Relative density of prepared samples amounted to 97,999,5\%. Chemical composition of samples was controlled by $\mathrm{X}$-ray fluorescence analysis on spectrometer with wavelength dispersion ARL OPTIM'X manufactured by Thermo Fisher Scientific.

According to the common viewpoint the high coercitive state is formed in $\mathrm{Fe}-\mathrm{Cr}$-Co alloys due to the decomposition of high temperature BCC a - solid solution on two isomorphous BCC $\alpha_{1}$ and $\alpha_{2}$ solid solutions occurring by a spinodal mechanism, where $\alpha_{1}$ phase is enriched by iron 
and cobalt and $\alpha_{2}$ phase is enriched by chrome [7]. Heat treatment is the most important operation resulting in the formation of nanocrystalline structure which determines the main material properties. Thermomagnetic treatment of samples was performed in the laboratory furnace equipped with armored electromagnet in magnetic field above 240 $\mathrm{kA} / \mathrm{m}$, the temperature in which was kept and monitored by programmed device PROTERM and chromel-alumel thermocouple. Heat treatment was conducted in standard laboratory muffle furnaces with programmed device PROTAR 101 and platinum-rhodium couple. The scheme of the alloy treatment is shown in figure 1.

Magnetic hysteresis properties $\left(\mathrm{B}_{\mathrm{r}}, \mathrm{H}_{\mathrm{c}},(\mathrm{BH})_{\max }\right)$ were measured by hysteresismeter «Permagraph L EP-3». Error of measurements amounted to $3 \%$ for coercive force $\mathrm{H}_{c}$ and residual induction $\mathrm{B}_{r}$, and $6 \%$ for maximum energy product $(\mathrm{BH})_{\max }$. The surface of samples was cleaned from slag using abrasive disk before measurements of magnetic properties.

Usually optimization of magnetic hysteresis properties is performed by the method of design of experiments (DOE) [8-10]. Optimization was done by the software package Statgraphics Plus 5.1 и Statistica 5.0. The experiment design matrix was chosen as a composition plan $2^{2}$ plus star points. The starting heat treatment temperature of $660{ }^{\circ} \mathrm{C}(0)$ and cooling rate of $60{ }^{\circ} \mathrm{C} / \mathrm{h}(0)$ were taken as a zero level of experiment; increment of $\mathrm{T}_{2}$ was of $\pm 20^{\circ} \mathrm{C}(+1,-1)$, change of $\mathrm{v}_{1}- \pm 20^{\circ} \mathrm{C} / \mathrm{h}(+1,-1)$. All the samples were quenched in water from $1250{ }^{\circ} \mathrm{C}$ (15 minutes), then they were heated up to $700-720{ }^{\circ} \mathrm{C}$ and cooled down from $660{ }^{\circ} \mathrm{C}$ to $600{ }^{\circ} \mathrm{C}$ in the magnetic field at the rate of $60^{\circ} \mathrm{C} / \mathrm{h}$, further cooling was conducted up to $500{ }^{\circ} \mathrm{C}$ without field at the rate of $8{ }^{\circ} \mathrm{C} / \mathrm{h}$.

\section{Results and discussions}

Table 1 shows the results of experiment design on the study of magnetic hysteresis properties $\left(\mathrm{B}_{\mathrm{r}}, \mathrm{H}_{\mathrm{c}},(\mathrm{BH})_{\max }\right)$ of the hard magnet alloy $\mathrm{Fe}-25 \% \mathrm{Cr}-10 \% \mathrm{Co}-2 \% \mathrm{Mo}-0,5 \% \mathrm{Si}$.

Regression equation for $\mathrm{B}_{\mathrm{r}}, \mathrm{H}_{\mathrm{c}^{\prime}}(\mathrm{BH})_{\text {max }}$ are as follows:

$$
\begin{array}{r}
\mathrm{B}_{\mathrm{r}}=1,35-0,02 \times \mathrm{A}+0,001 \times \mathrm{B}- \\
-0,04 \times \mathrm{A}^{2}+0,03 \times \mathrm{A} \times \mathrm{B}-0,04 \times \mathrm{B}^{2} \\
\mathrm{H}_{\mathrm{c}}=28,09-4,4 \times \mathrm{A}+1,38 \times \mathrm{B}- \\
-0,92 \times \mathrm{A}^{2}-0,015 \times \mathrm{A} \times \mathrm{B}-4,4 \times \mathrm{B}^{2} \\
(\mathrm{BH})_{\text {max }}=18,9-3,3 \times \mathrm{A}+1,45 \times \mathrm{B}- \\
-1,75 \times \mathrm{A}^{2}-0,28 \times \mathrm{A} \times \mathrm{B}-4,78 \times \mathrm{B}^{2}
\end{array}
$$

The first equation terms (1-3) characterize the average value of magnetic hysteresis properties of the Fe-25\%Cr-10\%Co-2\%Mo-0,5\%Si alloy. Figure 2 shows standardized Pareto charts which allow determining statistical significance of each factor.

Pareto charts show that linear coefficient A (cooling rate) and quadratic coefficient of the factor B are statistically significant for regression equations (2) and (3), for regression equation (1) all the coefficients are not statistically significant.

Table 2 represents the results of the experimental and estimated values of magnetic hysteresis properties $\left(B_{r}, H_{c}\right.$, $\left.(\mathrm{BH})_{\max }\right)$ of the alloy studied by obtained regression equations.

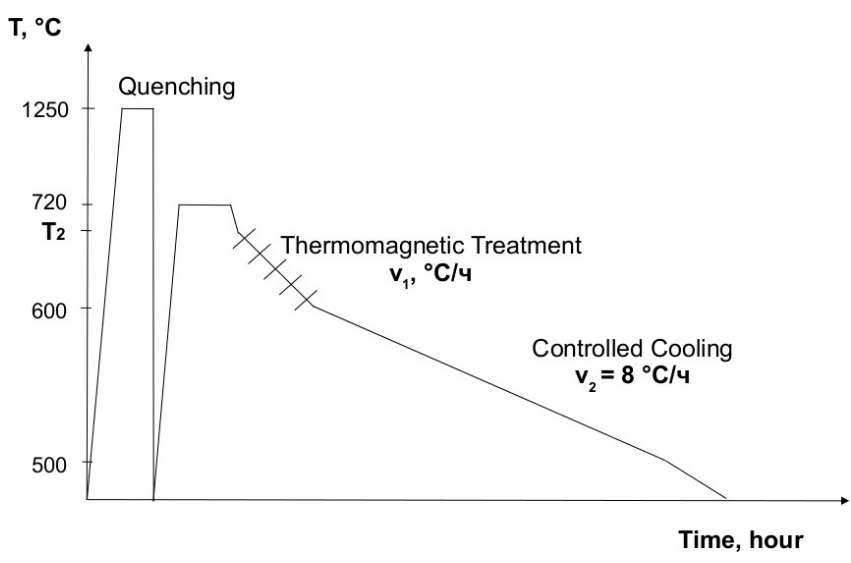

Fig. 1. Schematic diagram of heat treatment of the Fe-25\%Cr-10\%Co-2\%Mo-0,5\%Si alloy.

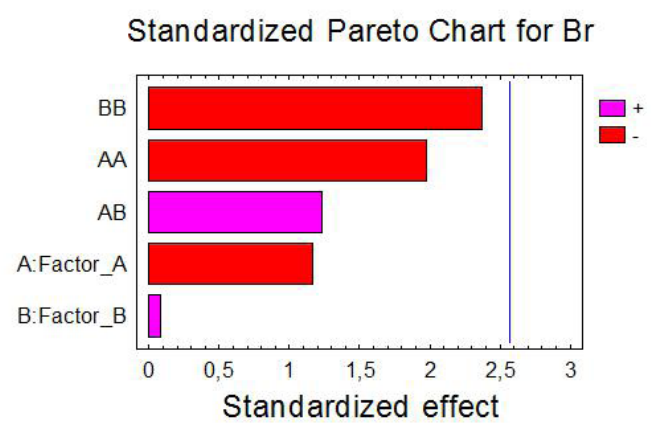

a

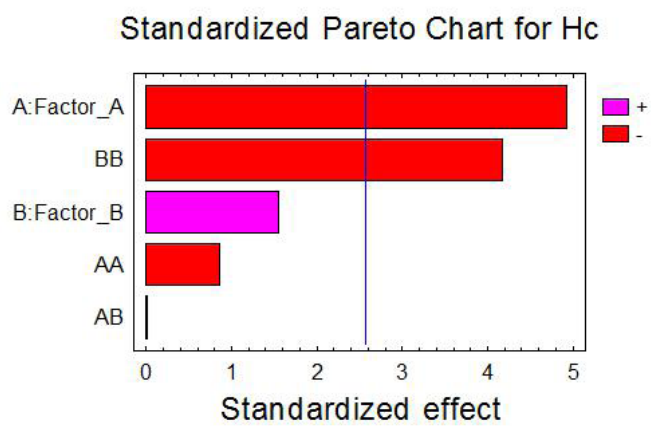

$\mathrm{b}$

Standardized Pareto Chart for BHmax

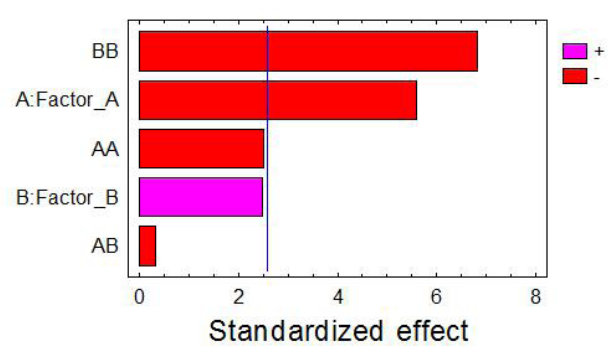

C

Fig. 2. Standardized Pareto charts for magnetic properties $B_{r}(a), H_{c}$ (b) and $(\mathrm{BH})_{\max }(\mathrm{c})$. 
Table 1. Magnetic hysteresis properties $\left(\mathrm{B}_{\mathrm{r}}, \mathrm{H}_{\mathrm{c}},(\mathrm{BH})_{\max }\right)$ of the Fe-25\%Cr-10\%Co-2\%Mo-0,5\%Si alloy

\begin{tabular}{|c|c|c|c|c|c|c|c|}
\hline № & \begin{tabular}{|c} 
Factor \\
$\mathrm{A}$
\end{tabular} & $\begin{array}{c}\mathrm{v}_{1}, \\
{ }^{\circ} \mathrm{C} / \mathrm{h}\end{array}$ & \begin{tabular}{|c} 
Factor \\
B
\end{tabular} & $\begin{array}{l}\mathrm{T}_{2}, \\
{ }^{\circ} \mathrm{C}\end{array}$ & $\begin{array}{c}\mathrm{B}_{\mathrm{r}} \\
\mathrm{T}\end{array}$ & $\begin{array}{c}\mathrm{H}_{\mathrm{c}^{\prime}} \\
\mathrm{kA} / \mathrm{m}\end{array}$ & $\begin{array}{c}(\mathrm{BH})_{\max } \\
\mathrm{kJ} / \mathrm{m}^{3}\end{array}$ \\
\hline 1 & 0 & 60 & 0 & 660 & 1,35 & 28,1 & 18,9 \\
\hline 2 & 0 & 60 & 0 & 660 & 1,35 & 28,1 & 18,9 \\
\hline 3 & 1 & 80 & 1 & 680 & 1,30 & 21,6 & 11,9 \\
\hline 4 & $-1,41$ & 31,8 & 0 & 660 & 1,31 & 30,8 & 20,1 \\
\hline 5 & 0 & 60 & 1,41 & 688,2 & 1,27 & 19,6 & 10,6 \\
\hline 6 & -1 & 40 & -1 & 640 & 1,33 & 27,8 & 14,4 \\
\hline 7 & -1 & 40 & 1 & 680 & 1,24 & 30,0 & 17,5 \\
\hline 8 & 1,41 & 88,2 & 0 & 660 & 1,20 & 17,8 & 8,6 \\
\hline 9 & 0 & 60 & 0 & 660 & 1,35 & 28,0 & 18,9 \\
\hline 10 & 0 & 60 & $-1,41$ & 631,8 & 1,21 & 14,9 & 6,0 \\
\hline 11 & 1 & 80 & -1 & 640 & 1,28 & 19,5 & 9,9 \\
\hline
\end{tabular}

Table 2. Experimental and estimated values for magnetic hysteresis properties $\left(\mathrm{B}_{\mathrm{r}}, \mathrm{H}_{\mathrm{c}},(\mathrm{BH})_{\max }\right)$ of the $\mathrm{Fe}-25 \% \mathrm{Cr}-10 \% \mathrm{Co}-2 \% \mathrm{Mo}-0,5 \% \mathrm{Si}$ alloy

\begin{tabular}{|c|c|c|c|c|c|c|}
\hline & \multicolumn{3}{|c|}{ Experiment } & \multicolumn{3}{c|}{ By Equations $(1-3)^{2}$} \\
\hline № & $\begin{array}{c}\mathrm{B}_{\mathrm{r}} \\
\mathrm{T}\end{array}$ & $\begin{array}{c}\mathrm{H}_{\mathrm{c}}, \\
\mathrm{kA} / \mathrm{m}\end{array}$ & $\begin{array}{c}(\mathrm{BH})_{\text {max }} \\
\mathrm{kJ} / \mathrm{m}^{3}\end{array}$ & $\begin{array}{c}\mathrm{B}_{\mathrm{r}} \\
\mathrm{T}\end{array}$ & $\begin{array}{c}\mathrm{H}_{\mathrm{c}} \\
\mathrm{kA} / \mathrm{m}\end{array}$ & $\begin{array}{c}(\mathrm{BH})_{\max } \\
\mathrm{kJ} / \mathrm{m}^{3}\end{array}$ \\
\hline 1 & 1,35 & 28,1 & 18,9 & 1,35 & 28,1 & 18,9 \\
\hline 2 & 1,35 & 28,1 & 18,9 & 1,35 & 28,1 & 18,9 \\
\hline 3 & 1,30 & 21,6 & 11,9 & 1,28 & 19,7 & 10,2 \\
\hline 4 & 1,31 & 30,8 & 20,1 & 1,30 & 32,5 & 20,1 \\
\hline 5 & 1,27 & 19,6 & 10,6 & 1,27 & 21,3 & 11,4 \\
\hline 6 & 1,33 & 27,8 & 14,4 & 1,32 & 25,8 & 13,9 \\
\hline 7 & 1,24 & 30,0 & 17,5 & 1,26 & 28,6 & 17,4 \\
\hline 8 & 1,20 & 17,8 & 8,6 & 1,24 & 20,1 & 10,8 \\
\hline 9 & 1,35 & 28,0 & 18,9 & 1,35 & 28,1 & 18,9 \\
\hline 10 & 1,21 & 14,9 & 6,0 & 1,27 & 17,4 & 7,4 \\
\hline 11 & 1,28 & 19,5 & 9,9 & 1,22 & 17,0 & 7,9 \\
\hline
\end{tabular}

Regression equations satisfactorily describe the experimental data within the limits of chosen parameters of heat treatment fluctuations; accuracy is commensurable with measurements accuracy.

Figure 3 represents the sections of response surfaces of the residual induction $\mathrm{B}_{r}$, the coercive force $\mathrm{H}_{c}$ and the maximum energy product $(\mathrm{BH})_{\max }$ in corresponding phase spaces.

These response surface sections allow visually evaluate the level of magnetic hysteresis properties of the alloy depending on the thermomagnetic treatment parameters. The starting temperature of preliminary aging of the alloy is the most influential factor as it changes dramatically the average size of strong magnetic $\alpha_{1}$ phase precipitates which specifies both the coercive force $\mathrm{H}_{\mathrm{c}}$ and the maximum energy product $(\mathrm{BH})_{\text {max }}$ value.

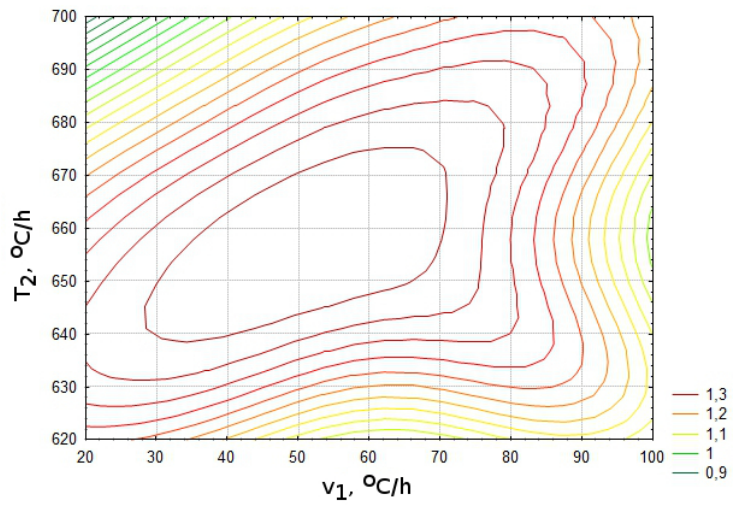

a

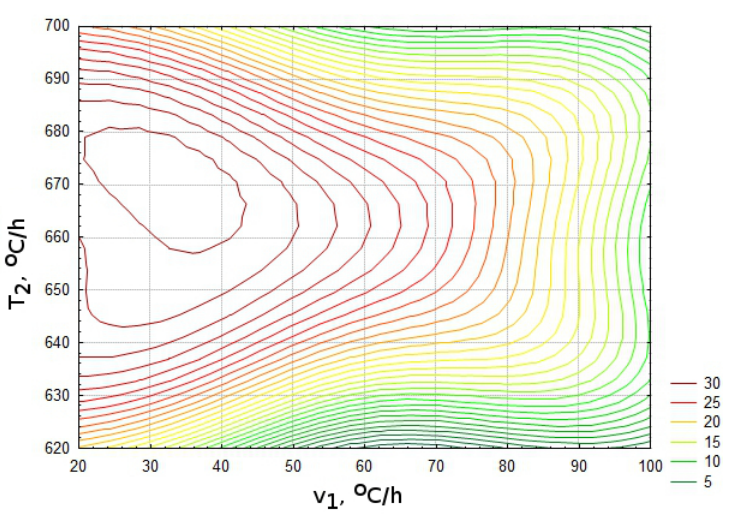

b

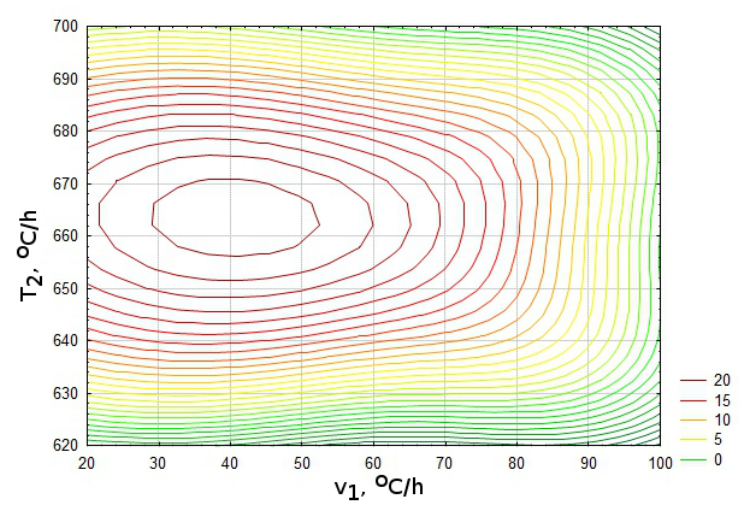

c

Fig. 3. Sections of the response surface plots $B_{r}(a), H_{c}(b)$ and $(\mathrm{BH})_{\max }(\mathrm{c})$. 
As seen from the charts, the optimum thermomagnetic treatment mode to get maximum value of the coercive force $\mathrm{H}_{\mathrm{c}}$ and the maximum energy product $(\mathrm{BH})_{\max }$ for the $\mathrm{Fe}-25 \% \mathrm{Cr}-10 \% \mathrm{Co}-2 \% \mathrm{Mo}-0,5 \% \mathrm{Si}$ alloy is a treatment by cooling in the magnetic field at the rate of $30-40{ }^{\circ} \mathrm{C} / \mathrm{h}$ from the temperature of $670-660^{\circ} \mathrm{C}$.

Due to uniqe possibility to regulate magnetic properties depending on heat treatment and attractive price (less content of scarce cobalt) the investigated hard magnetic alloy $\mathrm{Fe}-25 \% \mathrm{Cr}-10 \% \mathrm{Co}-2 \% \mathrm{Mo}-0,5 \% \mathrm{Si}$ can be used as the material for production of active part of rotor for synchronous hysteresis motors of certain capacity.

\section{Conclusions}

1. Values of the coercive force $\mathrm{H}_{c}$ within the limits of 14,8 $30,8 \mathrm{KA} / \mathrm{m}$, the maximum energy product $(\mathrm{BH})_{\max }-6,0-20,1$ $\mathrm{kJ} / \mathrm{m}^{3}$ at the residual induction value $B_{r}-1,20-1,35 \mathrm{~T}$ were obtained for the Fe-25\%Cr-10\%Co-2\%Mo-0,5\%Si powder alloy using various heat treatment modes.

2. Value of the coercive force $\mathrm{H}_{c}$ and value of the maximum energy product $(\mathrm{BH})_{\text {max }}$ are sensitive to the starting temperature of heat treatment and to the cooling rate, but the residual induction value $B_{r}$ is not sensitive to the chosen heat treatment parameters.

3. The Fe-25\%Cr-10\%Co-2\%Mo-0,5\%Si powder alloy can be used not only in permanent magnets production but also as a material for rotors of synchronous hysteresis motors.

\section{References}

1. Vompe T.A., Milyaev I.M., Yusupov V.S. Perspectivnie materiali. № 4. 2013. P. 59-63. (in Russian).

2. Milyaev A.I., Kovneristy J.K., Efimenko S.P., Korznikova G.F. Physics and Chemistry of Materials Processing. 2003. № 3. P. 86-88. (in Russian).

3. Green M.L., Sherwood R.C., Chin G. Y., Wernick J.H., Bernardini J. IEEE Transactions on Magnetics. Vol. 16. No. 5. 1980. P. 1053-1055. DOI: 10.1109/TMAG.1980.1060872.

4. Green M.L., Sherwood R.C., Wong C. C. Journal of Applied Physics. 1982. 53(3). P.2398-2400.DOI: 10.1063/1.330824.

5. Chin T.-S., Chen T.H., Chen C. Y. Journal of Magnetism and Magnetic Materials. 1985. V. 50. P. 214-222. DOI: 10.1016/0304-8853 (85) 90185-4.

6. Artamonov E. V., Liebman M. A., Rudanovsky N. N. Steel. № 6. 2007. P. 65 - 68. (in Russian).

7. Kaneko H., Homma M. and Nakamura K. AIP Conference Proceedings. Magnetism and Magnetic Materials. 1971. № 5. P. 1088 - 1092. DOI: 10.1063/1.2953814.

8. Alymov M.I., Ankudinov A.B., Zelensky V.A., Milyaev I. M., Yusupov V.S. Physics and Chemistry of Materials Processing. № 3. 2011. P. 18 -25. (in Russian).

9. Prutskov M.E., Milyaev I.M., Yusupov V.S., Milyaev A.I. Physics and Chemistry of Materials Processing. № 3. 2011. P. 38 - 42. (in Russian).

10. Nalimov V.V., Chernova N.A. Statistical methods for planning of extreme experiments. M.: Nauka. 1965. (in Russian). 